\title{
Micro Arc Oxidation of Wire Arc Sprayed Al-Mg6, Al-Si12, Al Coatings on Low Alloyed Steel
}

\author{
Levent Cenk Kumruoglu, Fatih Ustel, Ahmet Ozel, Abdullah Mimaroglu \\ Faculty of Engineering, University of Sakarya, Esentepe Campus, Sakarya, Turkey \\ E-mail:lkumruoglu@sakarya.edu.tr,ozel@sakarya.edu.tr, \\ ustel@sakarya.edu.tr,mimarog@sakarya.edu.tr \\ Received October 28, 2010; revised June 11, 2011; accepted June 20, 2011
}

\begin{abstract}
Micro arc oxidation of wire arc sprayed Al-Mg6, Al-Si12 and Pure Al coatings on low carbon steel has been performed. The coatings have been analyzed using optic microscope, scanning electron microscopy, X-ray diffraction and surface roughness tester. At the same time, voltage and current regimes are investigated during the process. Then after MAO process, uniform $\mathrm{Al}_{2} \mathrm{O}_{3}$ ceramic coatings have been deposited on surface of Al-Mg6, Al-Si12 and Al coated steel. The ceramic coatings are mainly composed of $\mathrm{Al}_{2} \mathrm{O}_{3}$ phase. The compound coatings show high hardness and significant improvement of corrosion resistance property.
\end{abstract}

Keywords: Micro Arc Oxidation, Plasma Electrolytic Oxidation, Arc Spray, AISI 1010 Steel, MAO, PEO, SEM, XRD

\section{Introduction}

Studies focusing on how to improve the protection of steel against degradation by corrosion or wear are the main objective of researchers of processes and materials, always aiming to reduce costs by preserving the structure and increasing its service life.

Cathodic and anodic protection, coatings and painting are some of the methods employed to combat degradation [1]. Micro Arc Oxidation (MAO), also known as Plasma Electrolytic Oxidation, is globally gaining increased popularity as a novel means of deposition dense, thick, ultra-hard ceramic coatings on metals like $\mathrm{Al}, \mathrm{Mg}$, $\mathrm{Ti}, \mathrm{Zr}$ and $\mathrm{Nb}$ and their alloys with an objective to improve the wear, thermal, chemical, corrosion, oxidation resistance. MAO process employs Electro-chemical and Electro-thermal oxidation in alkaline electrolytic medium with an alternating and direct current -high voltage surface multiple discharges [2,3]. During oxidation, many visible spark or micro arc spots move rapidly on the metal surface in aqueous solution. The local instantaneous temperature and pressure inside these micro arc discharge channels can reach 103 - $104 \mathrm{~K}$ and 102 - 103 MPa, respectively [4].

In the Arc Spray Process a pair of electrically conductive wires such as $\mathrm{Al}, \mathrm{Al}-\mathrm{Si} 12, \mathrm{Al}-\mathrm{Mg} 6$ are melted by means of an electric arc. The molten material is atomized by compressed air and propelled towards the substrate surface. The impacting molten particles on the substrate rapidly solidify to form a coating. Compared to other thermal spray methods, wire arc spray is considered as a simple, low cost, efficient coating process [5-12].

The purpose of this study was to explore the potential of the wire arc spray process in applying Al-Mg6, $\mathrm{Al}-\mathrm{Si} 12$ and Pure $\mathrm{Al}$ coatings on low carbon steel and examination of micro arc oxidation of arc spray coatings. This paper discusses the coating properties and microstructure through changes in spray processes and micro arc oxidation of coated samples

\section{Experimental Procedure}

Sticks made of low carbon steel (AISI 1010) of $17.5 \mathrm{~mm}$ and length of $50 \mathrm{~mm}$ were used as substrates. Aluminum alloys, $\mathrm{Al}-\mathrm{Mg} 6, \mathrm{Al}-\mathrm{Si} 12$ and Pure $\mathrm{Al}$, were used as the arc spraying material. The current employed in arc spraying were 100,200 and 300 A respectively at the spraying voltage of 28,30 and $32 \mathrm{~V}$, and the distance of spraying between the work piece and spraying gun were 150 and $200 \mathrm{~mm}$ at the compressed air pressure of 3 and 4 Bar. All wire arc sprayed coatings were carried out using robot arm to obtain homogeny coating thickness. Wires were sprayed using a electric wire arc spray gun and robotic system (Sulzer-Metco). Spray parameters 
used in tests are listed in Table $\mathbf{1 .}$

The thicknesses of all sample details of arc sprayed coatings were measured with Positector 6000. Also knoop and micro hardness was measured using hardness tester. Vickers microhardness measurements on all the coating cross-sections and top surface of coating have been carried out, all measurements have been performed at random locations on each sample.

Then micro arc oxidation studies were carried out for all arc sprayed samples. The micro arc oxidation processes were conducted on a high-power DC electrical source, a plexiglass container with a sample holder as the electrolyte cell, and a stirring and cooling system (Fig- ure 1).

Aqueous solutions of $5 \mathrm{~g} / \mathrm{L} \mathrm{Na}_{2} \mathrm{~B}_{4} \mathrm{O}_{7}$ (sodium tetraborate), $5 \mathrm{~g} / \mathrm{L} \mathrm{KOH}$ (Potassium hydroxid), 2 g/L Na $\mathrm{NO}_{4}$ (sodium phosphate), $20 \mathrm{~g} / \mathrm{L}$ glycerin and distilled water used as components of the electrolyte. The current density was approximately $12 \mathrm{~A} / \mathrm{dm}^{2}$. The solution temperature was controlled at $35^{\circ} \mathrm{C}$. After MAO processing, samples were rinsed thoroughly with water and then were dried in cool air. MAO parameters used in tests are listed in Table 2.

The surface morphology and cross-sections of the arc spray and micro arc coatings were examined by a JEOL600 scanning electron microscopy (SEM) and optic

Table 1. Deposition by the electric arc spray process.

\begin{tabular}{cccccc}
\hline Sample Code & Wire Type & Current & Voltage & Distance & Pressure \\
\hline AS1 & Al-Si12 & $100 \mathrm{~A}$ & $28 \mathrm{~V}$ & $15 \mathrm{~cm}$ & $3 \mathrm{Bar}$ \\
AS2 & Al-Si12 & $200 \mathrm{~A}$ & $28 \mathrm{~V}$ & $15 \mathrm{~cm}$ & $3 \mathrm{Bar}$ \\
AS3 & Al-Si12 & $300 \mathrm{~A}$ & $28 \mathrm{~V}$ & $15 \mathrm{~cm}$ & $3 \mathrm{Bar}$ \\
AS4 & Al-Si12 & $100 \mathrm{~A}$ & $28 \mathrm{~V}$ & $15 \mathrm{~cm}$ & $4 \mathrm{Bar}$ \\
AS5 & Al-Si12 & $200 \mathrm{~A}$ & $28 \mathrm{~V}$ & $15 \mathrm{~cm}$ & $4 \mathrm{Bar}$ \\
AS6 & Al-Si12 & $300 \mathrm{~A}$ & $28 \mathrm{~V}$ & $15 \mathrm{~cm}$ & $4 \mathrm{Bar}$ \\
AS7 & Al-Si12 & $200 \mathrm{~A}$ & $28 \mathrm{~V}$ & $20 \mathrm{~cm}$ & $3 \mathrm{Bar}$ \\
AS8 & Al-Si12 & $200 \mathrm{~A}$ & $30 \mathrm{~V}$ & $20 \mathrm{~cm}$ & $3 \mathrm{Bar}$ \\
AS9 & Al-Si12 & $200 \mathrm{~A}$ & $32 \mathrm{~V}$ & $20 \mathrm{~cm}$ & $3 \mathrm{Bar}$ \\
AM1 & Al-Mg6 & $200 \mathrm{~A}$ & $28 \mathrm{~V}$ & $15 \mathrm{~cm}$ & $3 \mathrm{Bar}$ \\
AM1 & Al-Mg6 & $200 \mathrm{~A}$ & $28 \mathrm{~V}$ & $20 \mathrm{~cm}$ & $3 \mathrm{Bar}$ \\
AM1 & Al-Mg6 & $200 \mathrm{~A}$ & $28 \mathrm{~V}$ & $15 \mathrm{~cm}$ & $4 \mathrm{Bar}$ \\
A1 & Al\%100 & $200 \mathrm{~A}$ & $28 \mathrm{~V}$ & $15 \mathrm{~cm}$ & $3 \mathrm{Bar}$ \\
\hline
\end{tabular}

Note: AS: Al-Si12, AM: Al-Mg6, A: Al \%100.

Table 2. Experimental parameters of MAO treatment.

\begin{tabular}{ccccc}
\hline Sample Code & Treatment time & Electrolyte Temperature & $\mathrm{pH}$ & C. of E. \\
\hline AS2 & $150 \mathrm{~min}$ & $20-35^{\circ} \mathrm{C}$ & 13 & $15 \mathrm{mS}$ \\
AS2 & $100 \mathrm{~min}$ & $20-35^{\circ} \mathrm{C}$ & 13 & $15 \mathrm{mS}$ \\
AS2 & $50 \mathrm{~min}$ & $20-35^{\circ} \mathrm{C}$ & 13 & $15 \mathrm{mS}$ \\
AM1 & $150 \mathrm{~min}$ & $20-35^{\circ} \mathrm{C}$ & 13 & $15 \mathrm{mS}$ \\
AM1 & $100 \mathrm{~min}$ & $20-35^{\circ} \mathrm{C}$ & 13 & $15 \mathrm{mS}$ \\
AM1 & $50 \mathrm{~min}$ & $20-35^{\circ} \mathrm{C}$ & 13 & $15 \mathrm{mS}$ \\
A1 & $150 \mathrm{~min}$ & $20-35^{\circ} \mathrm{C}$ & 13 & $15 \mathrm{mS}$ \\
\hline
\end{tabular}

C. of E.: Conductivity of Electrolyte. 


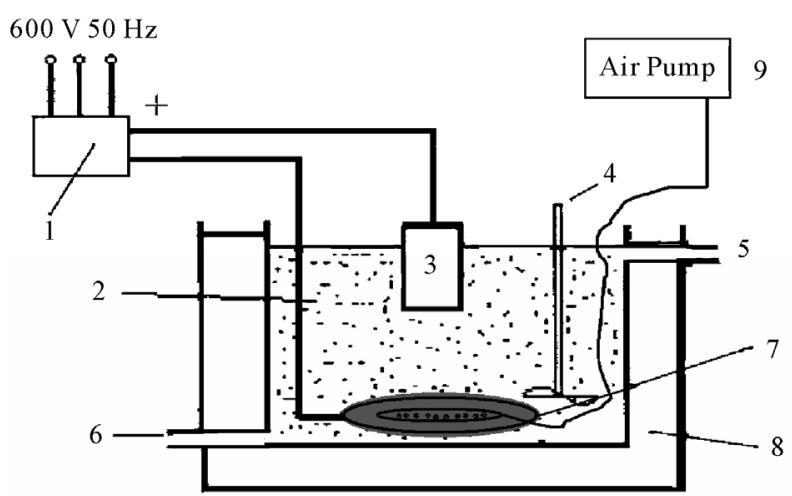

Figure 1. Schematic view of micro arc oxidation deposition system: 1, power supply and control system; 2, electrolyte; 3 , workpiece; 4 , mixer; 5 , cooling water inlet; 6 ,cooling water outlet; 7 , stainless-steel anode plate; 8 , plexiglass; 9 , air pump.

microcopy. Film phase composition was estimated using a Rigaku X-ray diffractometer (XRD) in the $2 \theta=10$ $90^{\circ}$ range.

\section{Results and Discussions}

\subsection{The Effect of Process and Arc Spray Parameters on Microstructure and Microhardness Properties}

When a thermal spray coating is applied onto a surface, the process parameter during spraying is known to have a strong effect on coating properties.

Polished cross section of the arc spray deposits were digitized by using an optical microscope with a digital camera. The effect of increasing arc current, arc voltage, operating gas pressure and spray distance were presented in Figures 2, 3, 4 and 5 respectively.

Figures 6 and 7 shows the surface roughness, thickness and microhardness of wire sprayed upper layer of substrate using different process parameters.

Figure 8 gives the evolution of the microhardnes and coating thickness in function of arc current. As it can be seen in Figure 8 that high arc voltages cause high thickness and low hardness.

As can be seen in Figure 9, increasing the operating gas pressure increases the microhardness of surface. At the same time, the effect of arc current-arc voltage, arc current-spray distance on microhardness and coating thickness, were given in Figure 10 and Figure 11.

\subsection{SEM-EDS and XRD Studies of Arc Spray Coatings and MAO Process}

Investigation of coatings microstructure revealed dependence of structure morphology on process parameters.

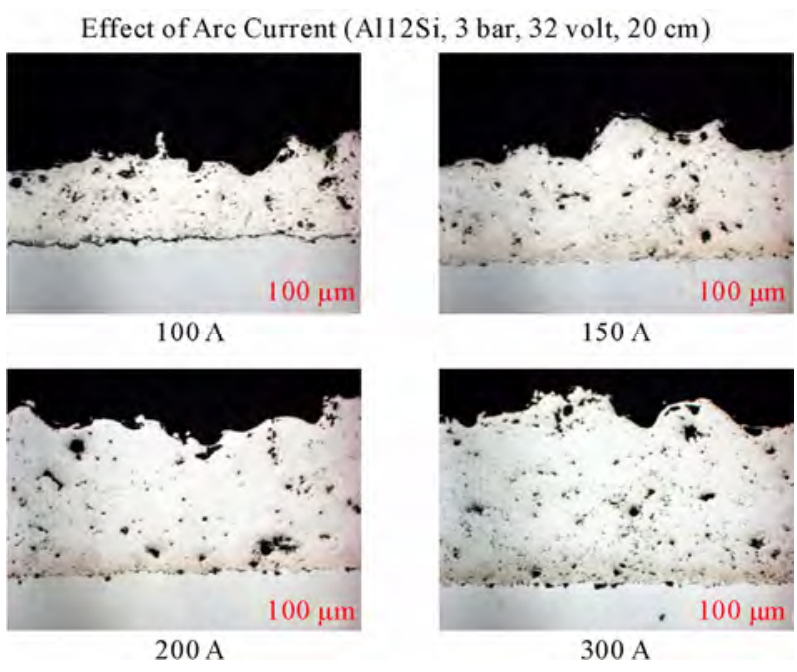

Effect of Arc Current (Al12Si, 3 bar, 28 volt, $15 \mathrm{~cm}$ )
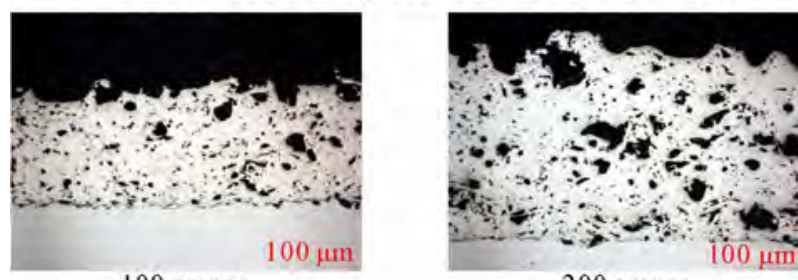

200 amper

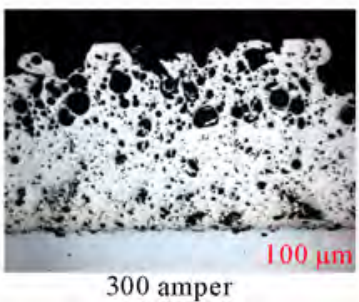

Figure 2. Effect of arc current on cross-section microstructure properties of AISi12 wire coated onto carbon steel.

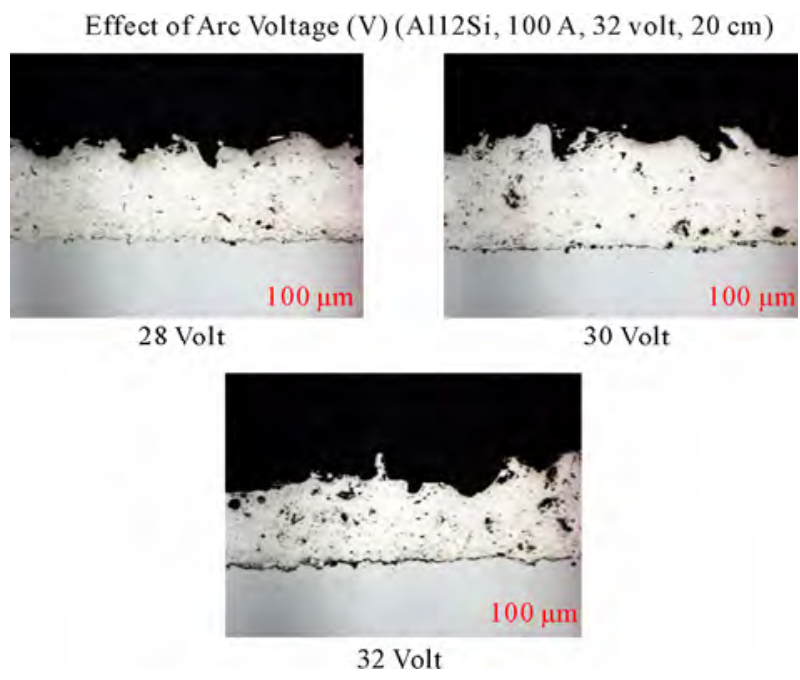

Figure 3. Effect of arc voltage on cross-section microstructure properties of Al-Si12 wire coated onto the carbon steel. 
Effect of Operating gas pressure (Al12Si, 300 amper, 28 volt, $15 \mathrm{~cm}$ )
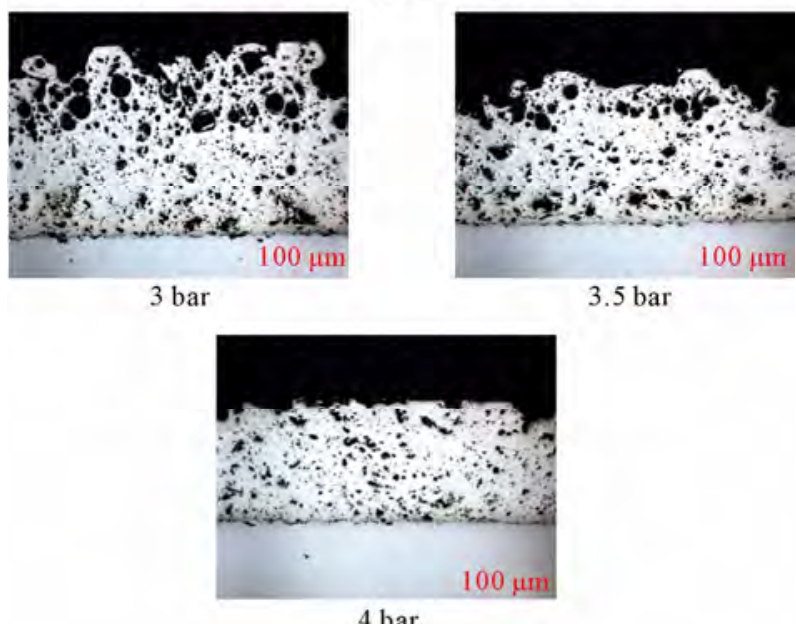

(a)

Effect of Operating gas pressure (Al12Si, 100 amper, 28 volt, $15 \mathrm{~cm}$ )
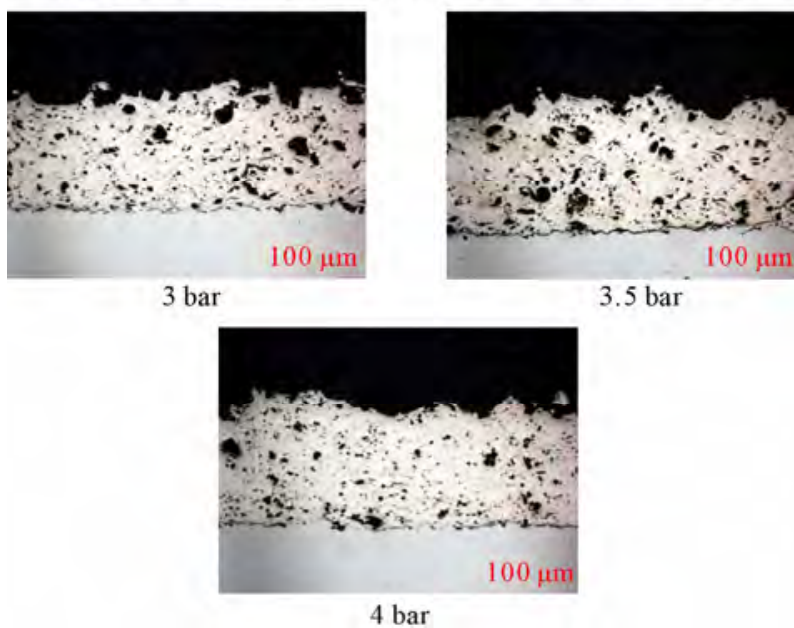

(b)

Figure 4. Effect of operating gas pressure and arc current on microstructure. (a) (Al-12Si, $300 \mathrm{~A}, 28 \mathrm{~V}, 15 \mathrm{~cm})$; (b) (Al-12Si, 100 A, 28 V, 15 cm).

The experimental studies showed that; the coating thickness of the arc sprayed layer increased and the micro hardness of layer decreased with the increase of arc current from $100 \mathrm{~A}$ to $300 \mathrm{~A}$. It is claim that, increasing the arc current increases the wire feed speed. The deposition rate is directly tied to the wire feed speed of the arc spraying process.

Increasing the operating gas pressure produces moredense and lower thickness of coated layer. Increase in operating gas pressure influences the micro hardness of deposited layer. As the operating gas pressure increased, the hardness of arc spray coatings increases Figures 6-12. The average Knoop hardness of Al-Mg6, Al-Si12 and Al were given in Figure 12.
Effect of spray distance (cm) (A112Si, 28 volt, 3 bar)
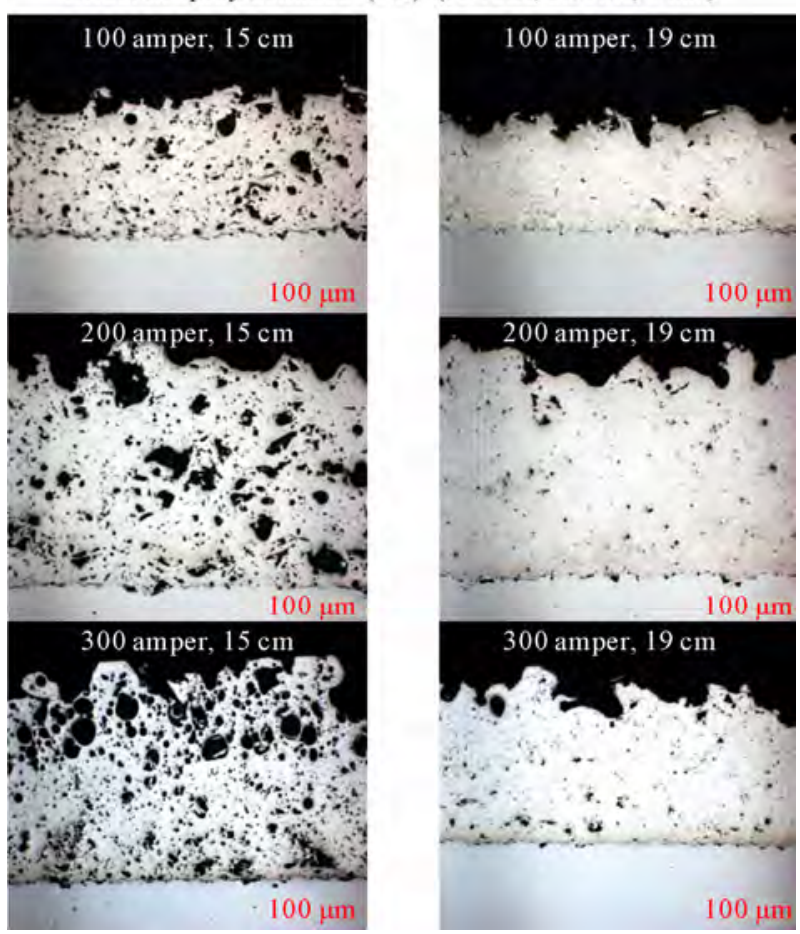

Figure 5. Effect of spray distance on microstructure of arc sprayed coating (Al-12Si, $28 \mathrm{~V}, 3$ bar).

The hardness test results revealed that the hardness of the coatings increased and thickness of coatings decreased with increasing spray distance, in the all coating fabricated with the wire arc spray. This occurs because with the increase in the spray distance, the temperature of the sprayed particles decreases, the amount of air taken in the spray increases and, as a result, the cooling rate of the coating increases. It also found that the increases of coating thickness were lowered the hardness and enhanced the porosity and the coating roughness.

Figures 13 and 14 show the cross section view of arc sprayed coating using Al-Mg6 wire. EDS analyses reveals that the atomized particles were oxidized while arc spraying. In the air wire arc spray process, the oxide content is relatively high due to oxidation of the molten particles. The quantitative analysis reveals that the amount of oxides in the coating increases when increasing air-flow rate. During spraying, the effect of air-flow rate causes significant in-flight oxidation of the molten particles because increasing air-flow rate leads to higher gas stream velocities which in turn break up the molten particles into smaller ones [13]. This affects the break voltage level while micro ac oxidation process. Typical micrographs of coatings produced by the MAO technique on an Al-Mg6 arc-sprayed coating, obtained using scanning electron microscopy, are shown in Figure 15.

In order to understand the composition characteristics, 

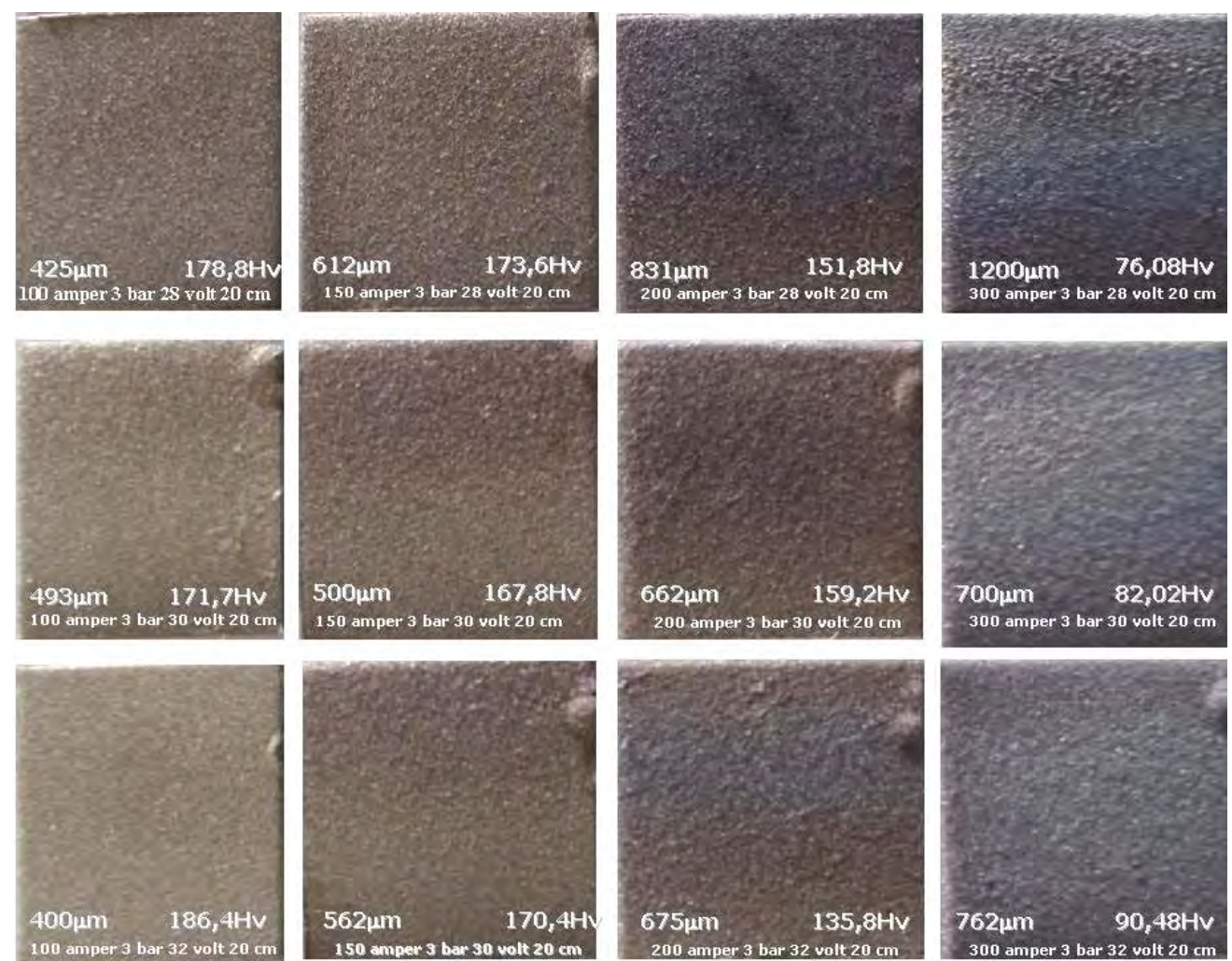

Figure 6. Coating thickness and micro hardness properties of arc sprayed coatings (Spray Distance $20 \mathrm{~cm}$ ).
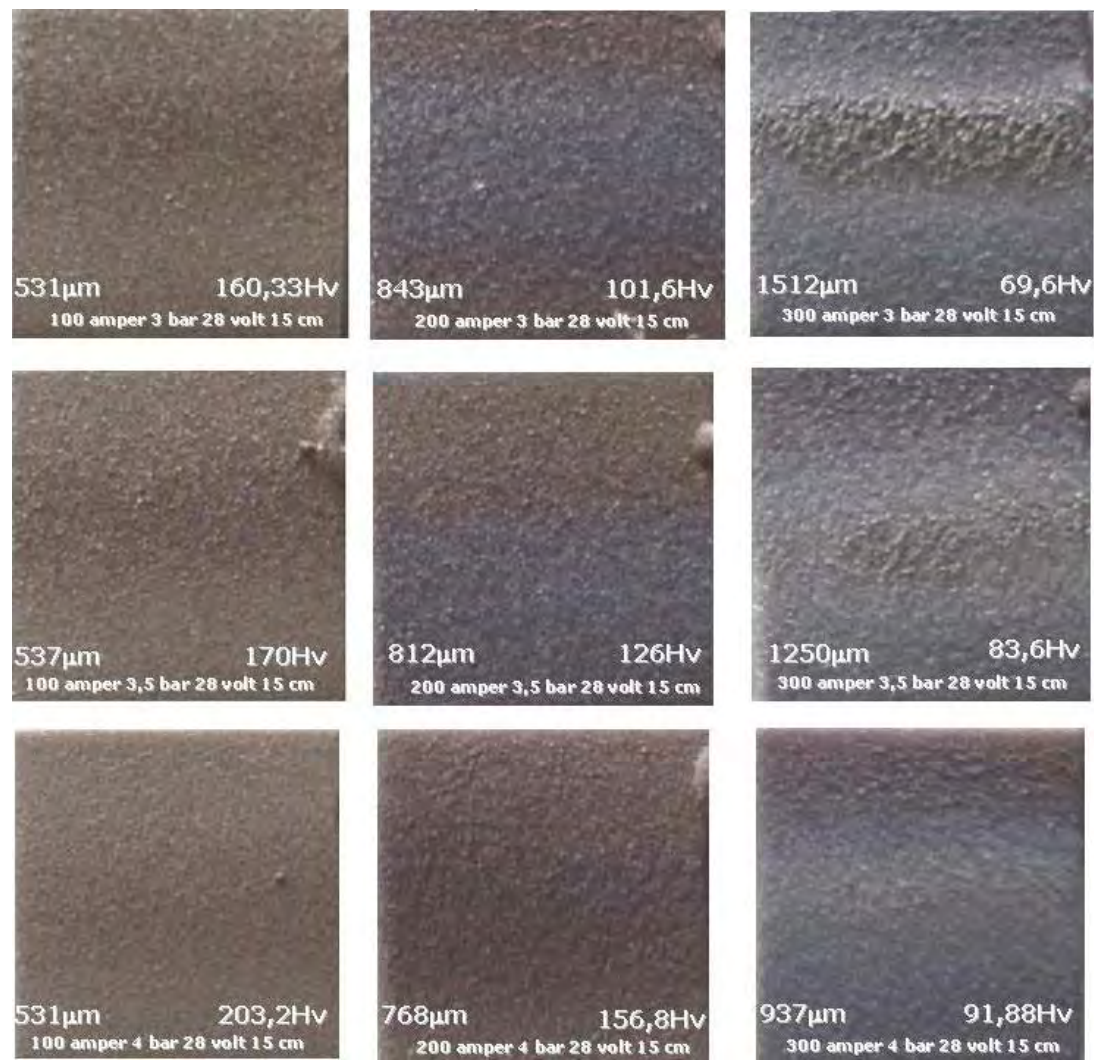

Figure 7. Coating thickness and micro hardness properties of arc sprayed coatings (Spray Distance $15 \mathrm{~cm}$ ) 

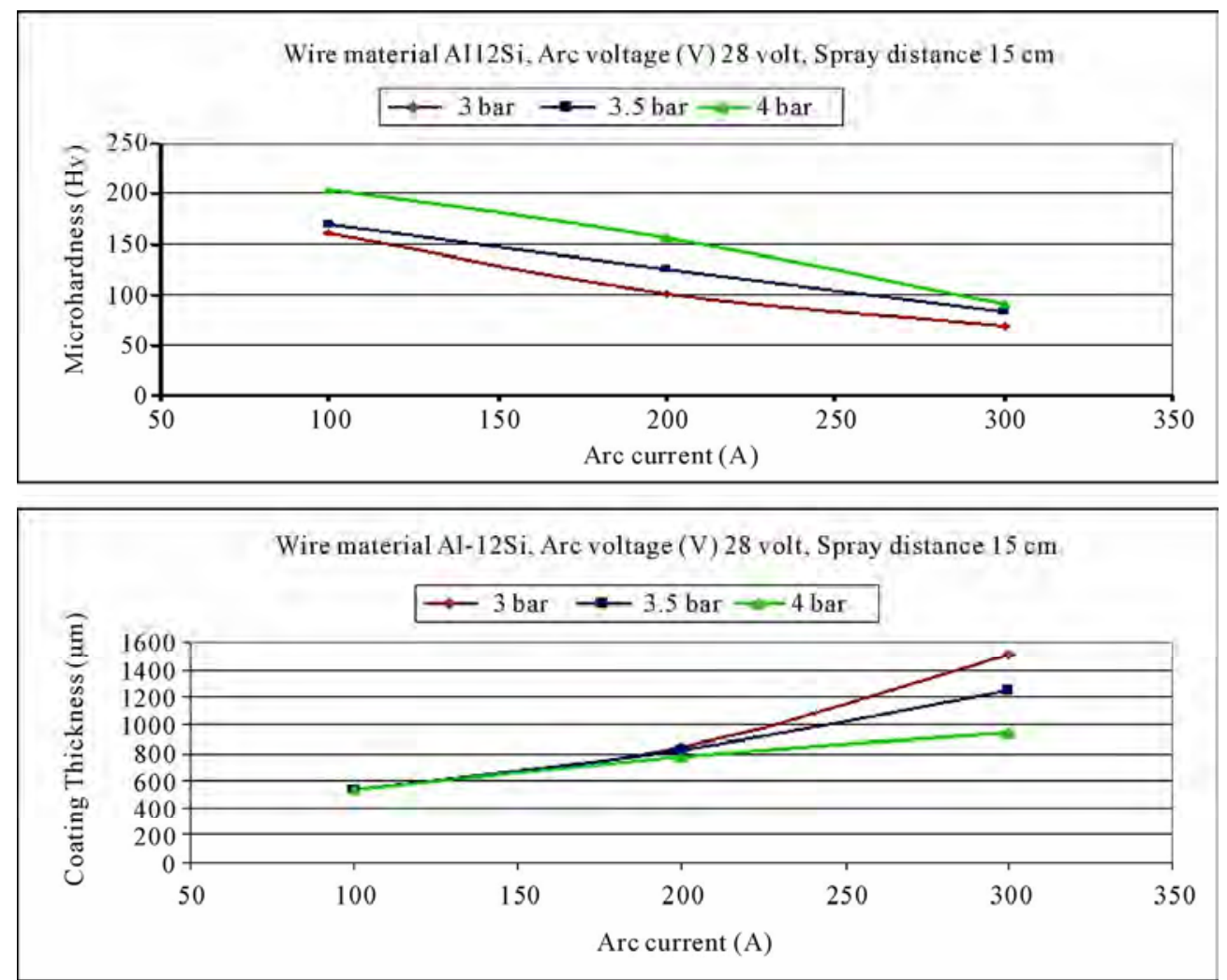

Figure 8. Effect of arc current on microhardness and coating thickness of wire arc spray process.
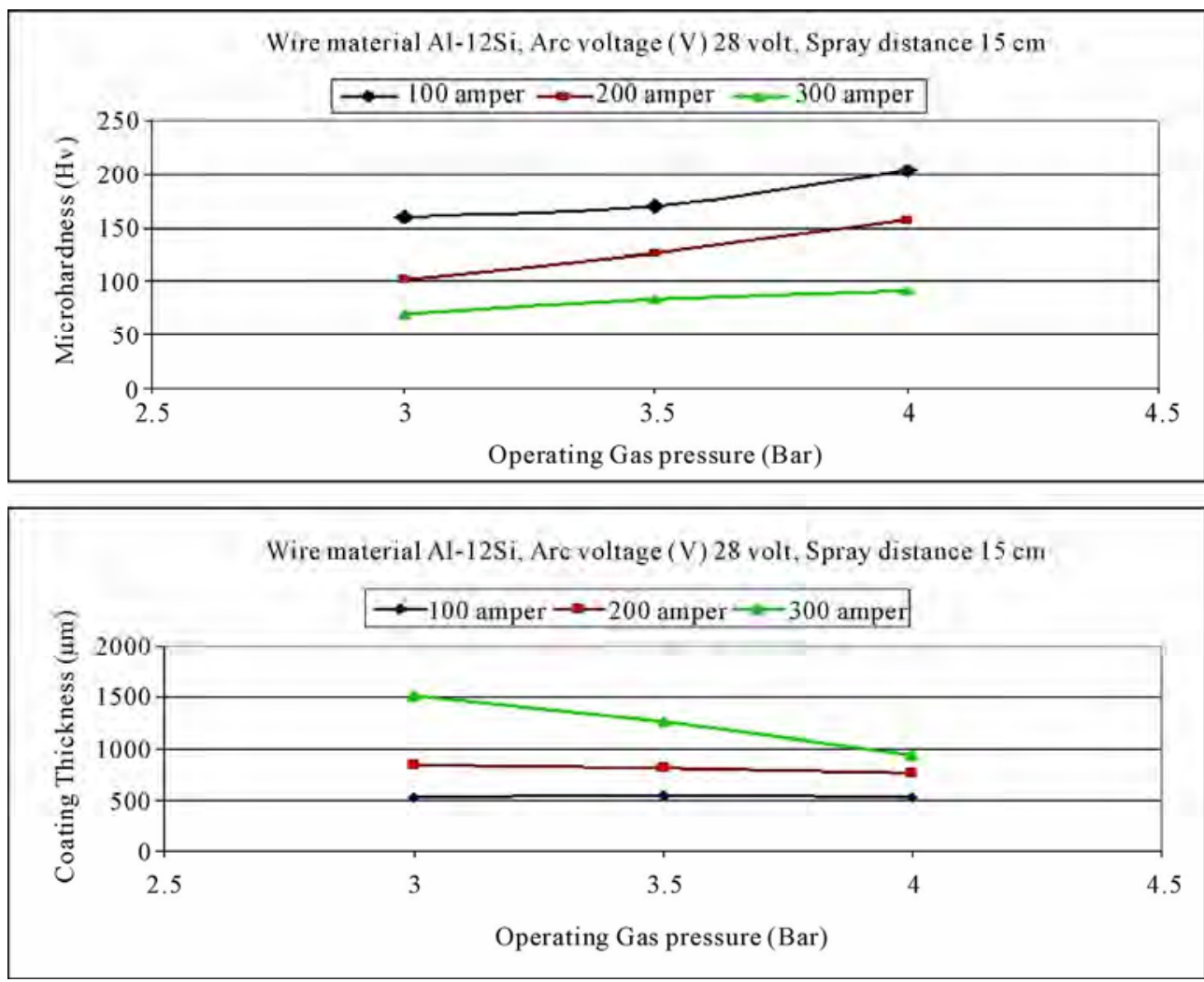

Figure 9. Effect of operating gas pressure on microhardness and coating thickness of wire arc spray process. 

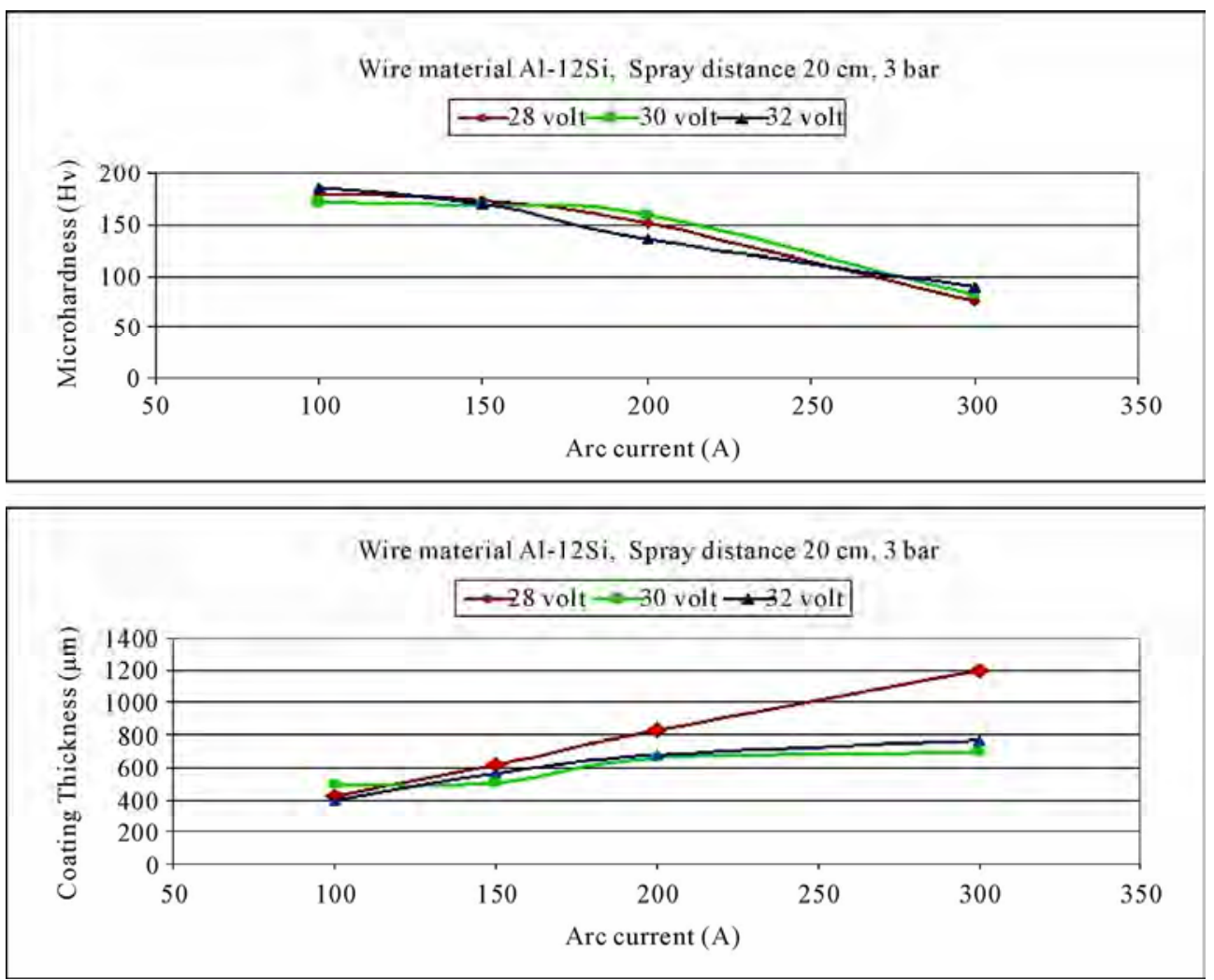

Figure 10. Effect of arc current and arc voltage on microhardness and coating thickness of wire arc spray process.
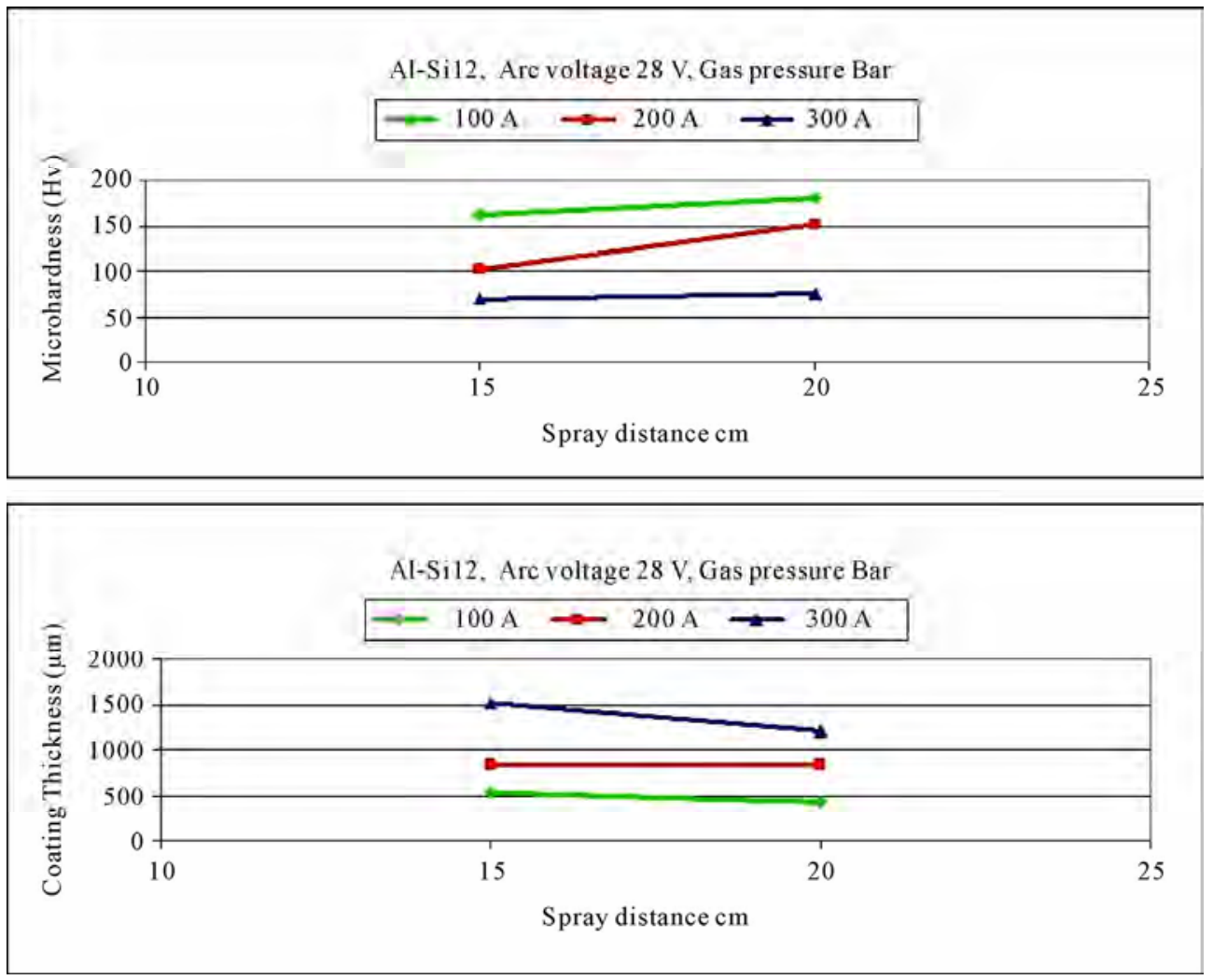

Figure 11. Effect of arc current and spray distance on microhardness and coating thickness of wire arc spray process. 

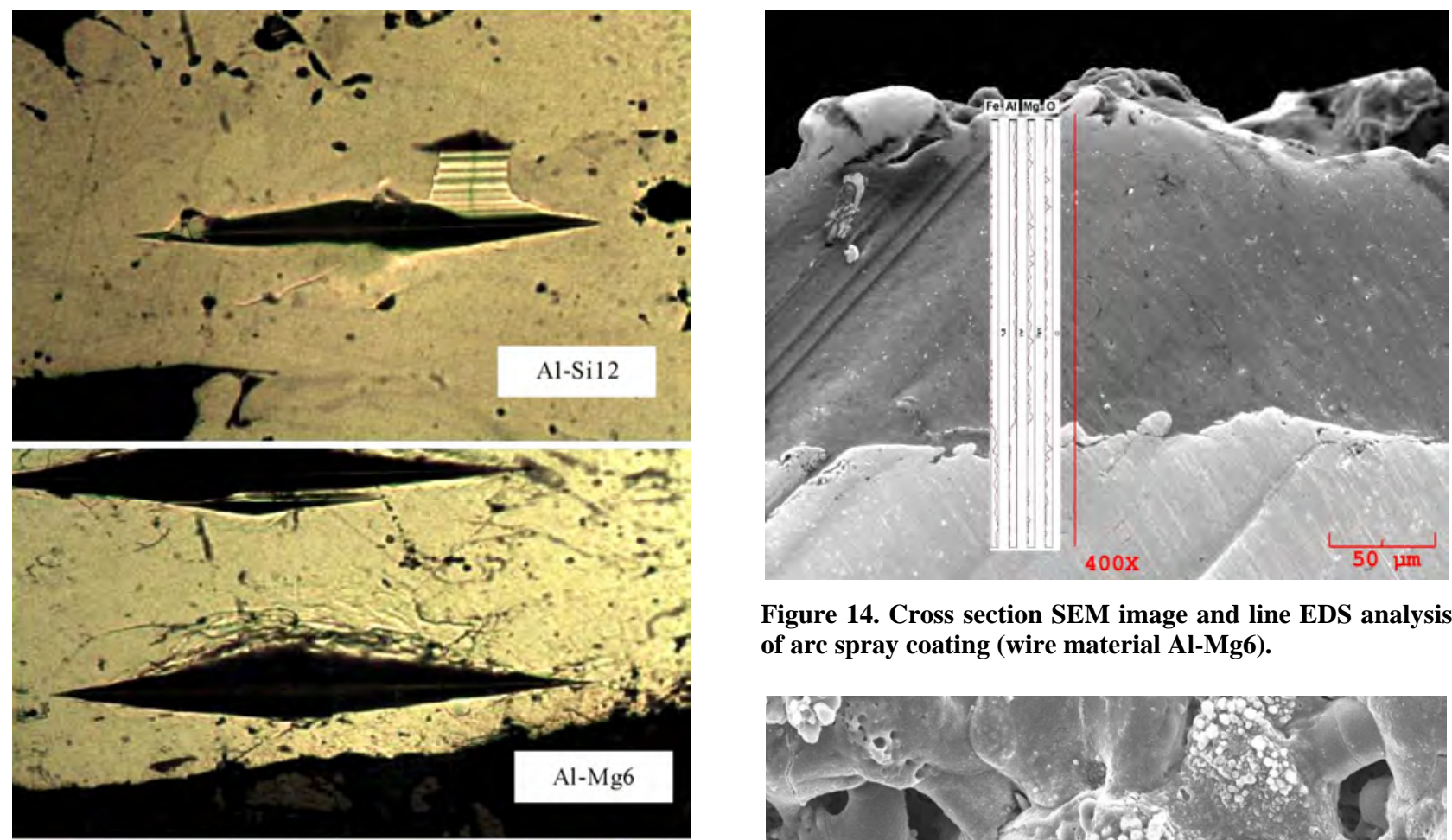

Figure 14. Cross section SEM image and line EDS analysis of arc spray coating (wire material Al-Mg6).

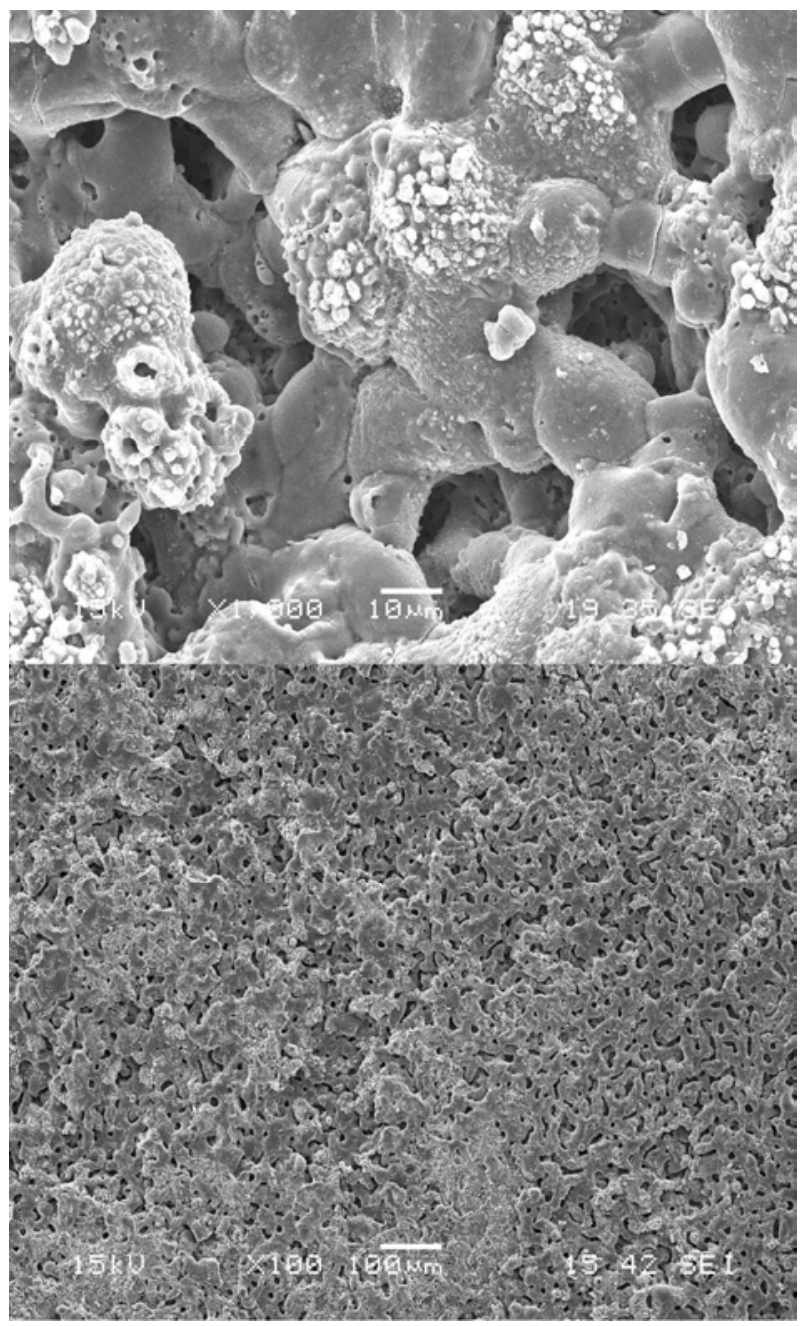

Figure 15. SEM micrographs of the specimen after micro arc oxidation treatment on arc sprayed layer using Al-Mg6 wire.

spray coating (wire material Al-Mg6). 


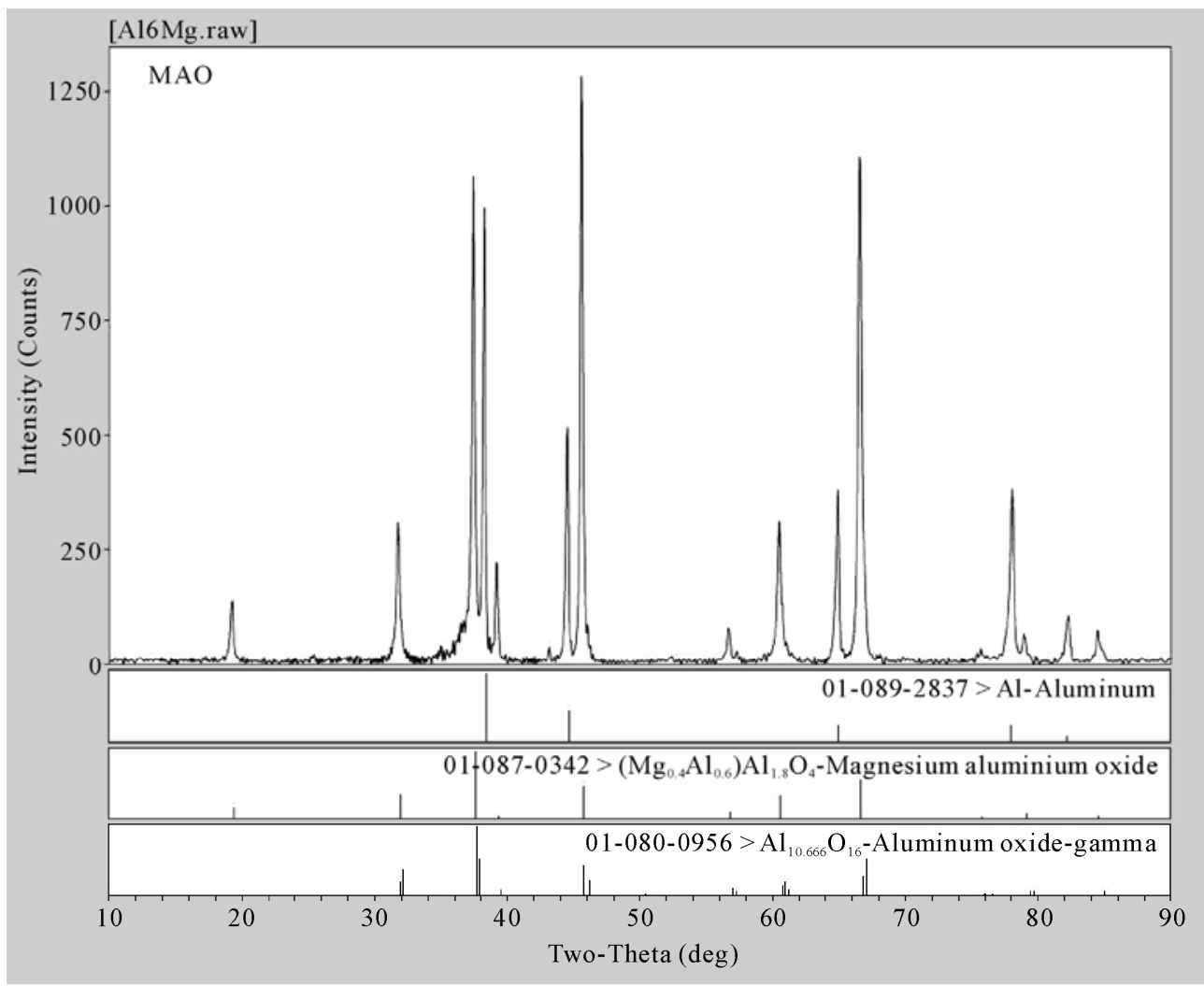

(a)

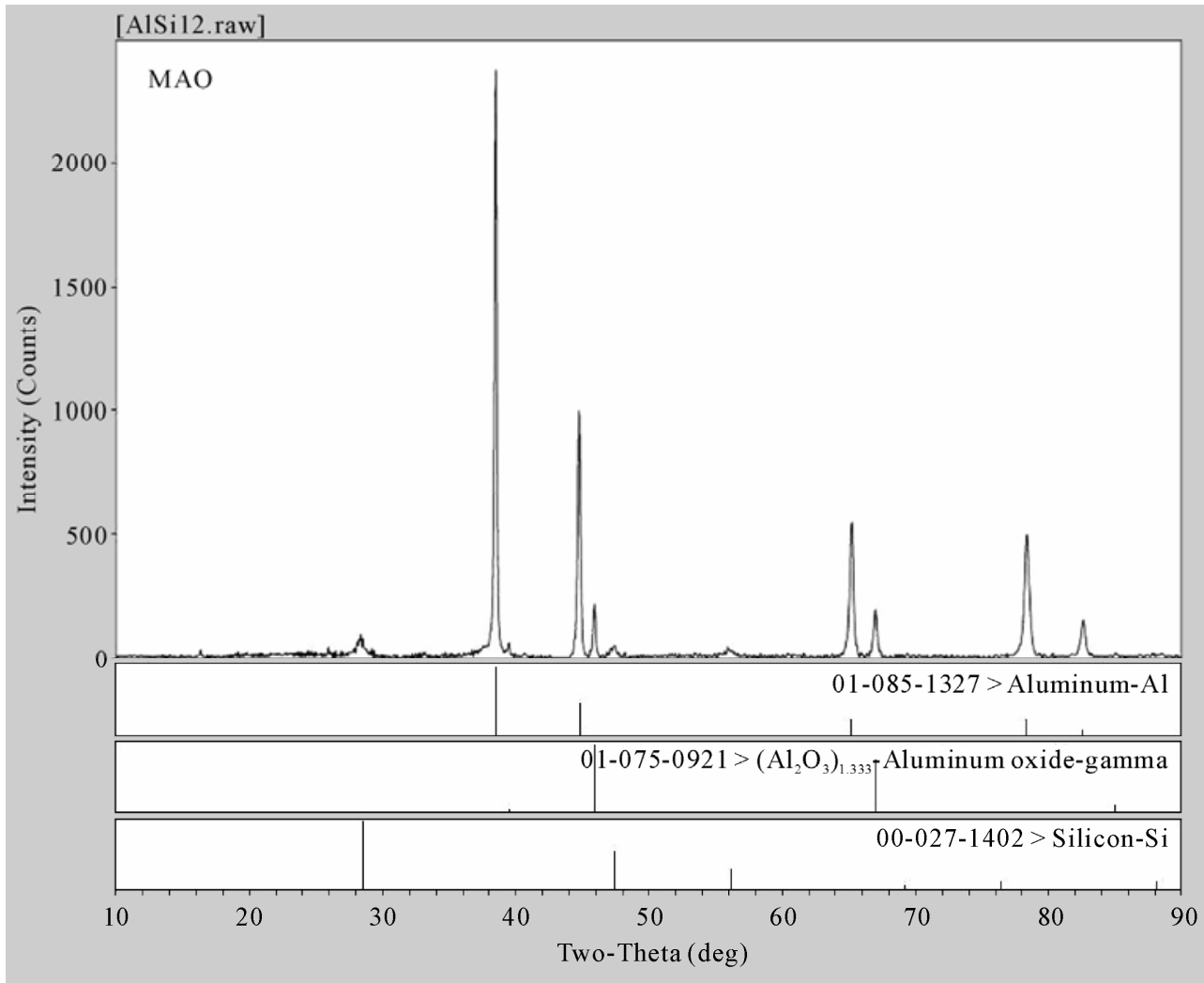

(b) 


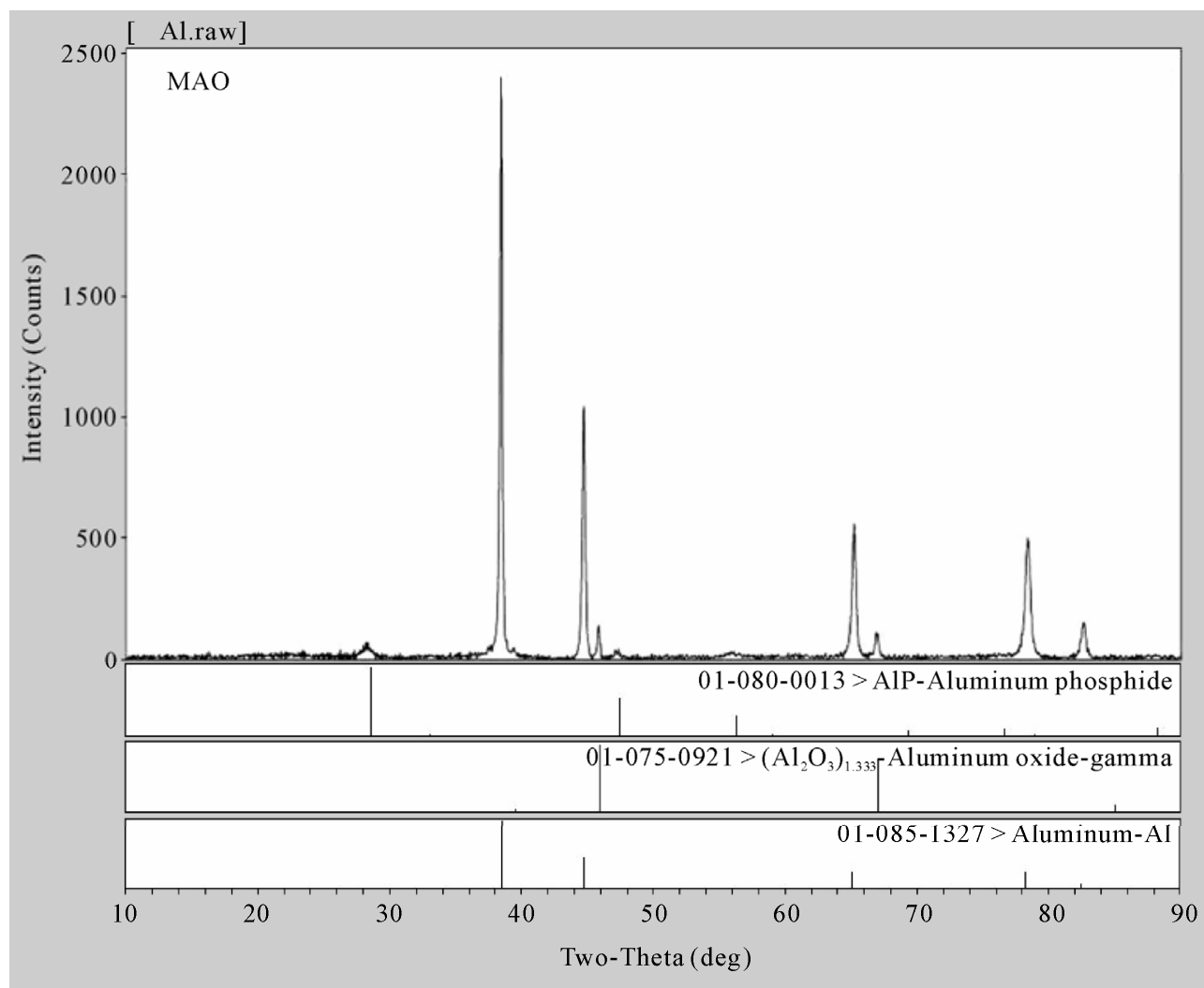

(c)

Figure 16. XRD analysis of oxide coatings produced by the MAO technique on arc sprayed aluminum coatings. (a) Al-Mg6 Wire Material; (b) Al-Si12 Wire Material; (c) Pure Al Wire Material.

element distributions were measured over the specimen surface by EDS technique. It was found that the specimen was mainly composed of three elements, magnesium, aluminum, oxygen (Al-Mg6), aluminum, oxygen silicon (Al-Mg12) and aluminum, oxygen (Al). The composition of the anodic coating was mainly crystalline oxide forms of $\mathrm{Al}$ and amorphous materials. The kinetics of MAO coatings is interface-controlled and largely dependent on the applied current density; the influence of electrolyte temperature, electrolyte additives and chemical composition of substrate. The final oxide forms of substrate are also largely dependent on chemical composition of substrate, the final phases of micro arc oxides samples were shown in Figure 16. The surface roughness of MAO coatings is a linear function of the final coating thickness, and increases with increasing coating thickness.

\section{Conclusions}

Multi-layer coatings have been performed on low carbon steel using a combined technique of wire arc spraying and micro arc oxidation.

The experimental results of arc spray coatings show that spray distance, arc voltage-current, operating gas pressure are very effective parameters in hardness and coating thickness.

MAO processes were carried out for anodizing materials such as Al-Mg6, Al-Si12, pure $\mathrm{Al}$ that coated on steel substrate using wire arc spray technique that are hard to anodize with conventional anodizing processes.

The chemical compositions of the substrate and electrolyte constituents exert a decisive influence on phase composition of the MAO films. XRD analysis results showed that the oxide films composed of Magnesium aluminum oxide, Aluminum oxide and $\mathrm{Al}$ for the Al-Mg6 arc sprayed substrate, Aluminum oxide, Al, Si for the Al-Si12 arc sprayed substrate and Aluminum phosphide, Aluminum oxide, $\mathrm{Al}$ for $\mathrm{Al}$ arc sprayed substrate.

\section{References}

[1] M. H. Regina, et al., "Comparison of Aluminum Coatings Deposited by Flame Spray and by Electric Arc Spray,” Surface and Coatings Technology, Vol. 202, No. 1, 2007, pp. 172-179. doi:10.1016/j.surfcoat.2007.05.067

[2] A. L. Yerokhin, X. Nie, A. Leyland, A. Matthews, S. J. 
Dowey, "Plasma electrolysis for surface engineering," Surface and Coatings Technology, Vol. 122, No. 2-3, 1999, pp. 73-93.doi:10.1016/S0257-8972(99)00441-7

[3] V. Pokhmurskii, et al., "Plasma Electrolytic Oxidation of Arc-Sprayed Aluminum Coatings," Journal of Thermal Spray Technology, Vol, 16, No. 5-6, 2007, pp. 998-1004. doi:10.1007/s11666-007-9104-X

[4] M. D. Klapkiv, "State of Electrolytic Plasma in the Process of Synthesis of Oxides Based on Aluminum," Materials Science, Vol. 31, No. 4, 1995, pp. 494-499. doi:10.1007/BF00559144

[5] C. Moreau, P. Gougeon and M. Lamontagne, "Influence of Substrate Preparation on the Flattening and Cooling of Plasma-Sprayed Particles," Journal of Thermal Spray Technology, Vol. 4, No. 1, 1995, pp. 25-33. doi:10.1007/BF02648525

[6] S. Shakeri and S. Chandra, "Splashing of Molten Tin Droplets on a Rough Steel Surface," International Journal of Heat and Mass Transfer, Vol. 45, No. 23, 2002, 4561-4575. doi:10.1016/S0017-9310(02)00170-9

[7] M. Fukumoto, E. Nishioka and T. Matsubara, "Flattening and Solidification Behavior of a Metal Droplet on a Flat Substrate Surface Held at Various Temperatures," Surface and Coatings Technology, Vol. 120-121, 1999, pp. 131-137. doi:10.1016/S0257-8972(99)00349-7

[8] N. Mehdizadeh, S. Chandra and J. Mostaghimi, "Formation of Fingers around the Edges of a Drop Hitting a
Metal Plate with High Velocity,” Journal of Fluid Mechanics, Vol. 510, 2004, pp. 353-373. doi:10.1017/S0022112004009310

[9] M. Pasandideh-Fard, V. Pershin, S. Chandra and J. Mostaghimi, "Splat Shapes in a Thermal Spray Coating Process: Simulations and Experiments," Journal of Thermal Spray Technology, Vol. 11, No. 2, 2002, pp. 206-217. doi:10.1361/105996302770348862

[10] A. McDonald, M. Lamontagne, C. Moreau and S. Chandra, "Impact of Plasma-Sprayed Metal Particles on Hot and Cold Glass Surfaces," Thin Solid Films, Vol. 514, No. 1-2, 2006, pp. 212-222.doi:10.1016/j.tsf.2006.03.010

[11] M. Fukumoto, E. Nishioka and T. Matsubara, "Flattening and Solidification Behavior of a Metal Droplet on a Flat Substrate Surface Held at Various Temperatures," Surface and Coatings Technology, Vol. 120-121, 1999, pp. 131-137. doi:10.1016/S0257-8972(99)00349-7

[12] A. Nobuyuki, et al., "Surface Modification of Al Sprayed Coatings by Direct Diode Laser Remelting Process," Transactions of JWRI, Vol. 35, No. 2, 2006),

[13] M. P. Planche, et al., "Relationships between in-Flight Particle Characteristics and Coating Microstructure with a Twin Wire Arc Spray Process and Different Working Conditions," Surface and Coatings Technology, Vol. 182, No. 2-3, 2004, pp. 215-226. doi:10.1016/S0257-8972(03)00873-9 